\title{
Development of indigenous collective strategies: A theoretical vision from modern management for development with Aymara identity
}

\author{
Rodrigo Ignacio Barra Novoa \\ Executive Director Center for Competitive Management and Territorial Innovation of Chile / Andean Lab. \\ Corresponding author email: rodrigo.barra.novoa@gmail.com |www.ingenia-t.cl \\ Researcher and Ph.D. student in Legal and Economic Sciences at the University Camilo José Cela \\ Madrid - Spain | Official Master's Degree in Territorial and Environmental Strategies in the Local Sphere from the \\ University of Huelva - Spain | Laboratory for Innovation, Growth, and Sustainability of the Andean Macro Region \\ ANDEAN-LAB
}

\begin{abstract}
The Aymara population constitutes the main social and cultural identity of the Arica and Parinacota Region in Chile and for more than five decades has continued to face a series of local difficulties due to globalization, technological change, and a neoliberal market economy with little government support. Numerous villages in the Andean foothills and high plateau continue to live in conditions of poverty. However, collective leadership has proven to be an innovative tool to address various market failures and institutional barriers that hinder their social and economic development at the territorial level. This article analyzes the main theoretical and practical postulates for collective strategies led by indigenous communities to be effectively developed in their cultural and territorial context.

Keywords---collective development, economic development, indigenous communities, social and cultural growth.
\end{abstract}

\section{Introduction}

In Chile, there is a perception in society that indigenous peoples are not being considered by the public policies created by the government to promote modernization and insertion into the national and international economy. International experiences indicate that the Aymara communities are unprotected in the face of authority decisions, unable to collectively resolve their challenges at the local level. The review of international literature indicates that modern leadership and organizational capacity require the restoration of indigenous leadership, as well as the adoption and transfer of ancestral knowledge between long-standing and more modern leaders. Also, leaders and their organizations, having to adapt to the rapid changes that are occurring, must meet the needs and aspirations of their communities while preserving their local heritage and identity.

Various approaches to economic development and static equilibrium imposed under the regionalization policy promoted by the military government, especially in the foothills and highlands of the Parinacota Province, sought to achieve sovereignty in these border areas and contribute to the rooting of its population, providing them with incentives for connectivity and infrastructure with a strong state bureaucratic apparatus in the territory, which to date has had a very modest contribution to the economic development of indigenous communities. The latter has recently been recognized by the institutional agents of the region, seeking to assume new strategies and work methodologies that internally strengthen development processes in the local population, preferably oriented to the management of productive, human, cultural, and environmental resources, practically the only thing available for their development.

Considering the above, development cannot exclude any social group, at least the existence of development alternatives for the population must be guaranteed, so the communities and local leaders have gradually awakened their concerns for a collective renewal and strategy for their organizations and communities, which becomes relevant as a means to claim for a better quality of life in their territories. 


\section{Literature Review}

The expansion of the topic of indigenous development is forcing public and private agents to adopt tools from the business sector and apply them within the lines of organizational strengthening to achieve better performance in the commercial and cultural activities of indigenous communities in Chile. According to this postulate, idiosyncrasy, cultural context, and ancestral community management practices recognize the importance of wisdom, leadership, and the community's narratives to achieve organizational success, which implies a process of cooperation, relationships, and lasting exchanges (Davis, 1997; Popp et al., 2013).

While it is not the aim of this paper to agree on all the political, social, and operational postulates of the collective strategy, its implementation implies a set of routines and procedures. The general hypothesis, although not exclusive, indicates that the collective strategy requires proper planning, linking objectives, indicators, and goals to successfully carry out an adequate strategic implementation. In this sense, the efficiency of the collective strategy is related to the closeness of the organization to its management boundary and efficient leadership. If the organization is very well managed, it is surely the result of a correct application of tools such as the Balanced Scorecard or an efficient administration of the organization's resources and capabilities (Penrose, 1959).

Moreover, operational and social synergies are also strategic factors that could justify the expansion of leadership and the integration of different stakeholders. These synergies explain, at least in part, the provision of internal improvements, as well as the emergence of the search for better bargaining power between local communities and institutional actors in the territory. There are other possible sources of territorial value creation from the integration of all the elements of the strategic management system, which according to Kaplan \& Norton (1993) align the strategy's mission with the set of key performance measures around four perspectives: internal processes, customers, finance, learning, and growth.

This framework provides balance to the outcomes the organization needs to achieve. Therefore, the cause-andeffect reasoning of collective strategy, especially for the indigenous territorial context, invites local development policymakers to reflect on strategic thinking and leadership to create value, especially to support the implementation of collective issues. Authors such as Peter Drucker, Kenneth Andrews, Alfred Chandler, and Igor Ansoff (1962), identify the need to think the collective strategy in an articulated and dynamic way, which unifies the individual ideas of each of the functional areas of the organization and relates them to the political, social and competitive environment in which it operates.

The results component of the conceptual analysis explains some theoretical and practical elements of the literature on the development of collective strategies, which includes key components such as the analysis of the political, social, and ethical needs of organizations; methodologies for the evolution of collective strategies and their future opportunities; identification of opportunities to increase the impact of strategies on stakeholders; definition of the stakeholders that make up the organization; and a series of communicational, strategic and administrative inputs and knowledge to achieve the purposes of the collective organizational strategy.

\section{Methodology}

From the methodological point of view, the article is of an explanatory, descriptive, and comprehensive type, which analyzes the main contributions of modern strategic management to achieve an adequate development of an indigenous collective strategy. The research examines qualitative factors and explains a series of political, social, ethical, and operational areas that help to expose the scope of an adequate strategy. Also, the role of local actors is contextualized, which helps to explain the importance among the agents involved to enhance the impact on indigenous organizations, communities, and associative ventures. Additionally, a series of articles, documents, statistics, and expert consultations are examined, considering the scarce systematization of this type of research in the regions of Arica and Parinacota.

\section{Results of the Conceptual Analysis}

Analysis of the political, operational, and moral conditions of collective strategies between organizations and administrations

For years, there has been one organizational doctrine that has dominated the strategic landscape of the executive and management sectors: "The attainment of maximum shareholder value". In recent years, it has provoked controversy, with highly polarized positions, as it is a tool for measuring management performance, whether of a general or 
absolute nature (Clarke \& Friedman, 2016). However, surely due to these contrasting views and evolving market demands in a world of extreme change, the concept of VSM has become outdated. Now it matters not only to increase shareholder wealth but also social welfare. As Clarke \& Friedman (2016) explain, the VSM has shown that it could harm society for several causes, some of them for belittling the actions of the indigenous world and the lack of interest in helping development with impact.

The world is evolving, for better or worse, and entrepreneurs, especially those of ethnic origin, often fail to think through the implications for their companies or organizations (Kourdi, 2010). Verweire (2014) presents a statistical study on this strategy misapplication. The extent is that failure rates range from $40 \%$ to $90 \%$, which is high. Consequently, essential needs thus arise in the political, social, moral, and operational domains to help build strategies for more consistent organizational practices for the indigenous world and worldview.

In outlining the political needs for effective strategy implementation, the literature emphasizes the relevance of law admitting organizations as human beings, as much of them did not act socially years before, which is an unknown in international politics. Clarke \& Friedman (2016) consider this point of view and state that this would give the right to ask companies to behave as honest and ethical people. This becomes important to achieve an empathetic strategy. All political parties and territorial organizations need to change the way they govern (Barber et al., 2005). To achieve this, Barber found six key factors: community leadership, regulation and oversight, scrutiny and challenge, communication skills, partnership working, and political understanding.

From a societal point of view, the strategy could be based on capital investment, participating in profit and human value, and prioritizing societal and stakeholder satisfaction (Clarke \& Friedman, 2016) According to Hoffman (2014), it is also important to create a climate agenda. Currently, $85 \%$ of businesspeople agree that climate change is a human factor in contrast to $62 \%$ and $76 \%$ of the general population who also do so, but with almost half or onethird who still do not. From a moral standpoint, there is a need to focus on leadership, management, and accountability to stakeholders in general. In the case of operations, there are several scenarios to consider: for example, in the area of mergers and acquisitions, it is valuable to think of (sub)cultures as neither static nor fixed, but as dynamic social constructs that play a role in social integration (Van Marrewijk, 2016). In the case of digital transformation, the vision of partnering with third parties (e.g., indigenous communities or ethnic entrepreneurs) is part of a long adaptive journey of creating innovative local products.

\section{Methodologies for collective development based on collaboration}

Successfully achieving the aforementioned requirements in the political, social, ethical, and operational domains is no easy task. Homkes (2016) mentions that between two-thirds and three-quarters of companies fail to achieve the expected results of their strategies. Long-term results and paradigm shifts require a well-defined and efficient model. In reality, modeling replicable good practices result in known methodologies in the subject of Strategic Planning. But according to Verweire (2014), no methodology would be useful if the strategy is not established. To quote him: "[...] the first step is to get the formulation process right. Making sure that the different activities are aligned with the strategy and that collaborators are committed to making it work is essential, but secondary." Therefore, before any methodology or workshop application, Verweire (2014) mentions four essential core aspects to fully master at the outset: knowledge in the market, the product itself, value proposition, and operating model. It is also important to emphasize that strategy is fundamentally thought about the future fueled by information gathered in the past and present. But the future is not what it was and any environmental factors that make a difference must be considered (Strategic analysis). These variables are both of national and international context and variables within the organization. It is important to note that strategy is fundamentally thought about the future fed by information gathered in the past and present. But the future is not what it was and any environmental factors that make a difference must be considered (Strategic Analysis). These variables are both local, national and international context, and the variables are within the organization.

Therefore, the formulation process begins. The application of PEST analysis (political, economic, social, and technological variables) could summarize regional, national, and international contexts. However, a fundamental external context is also defined by the competitive arena. Porter's "Five Forces Model" can be used to define direct competition, the power managed by both suppliers and customers, and the threat of potential new entrants and/or substitutes for ethnically relevant products in the market.

But this planning is insufficient because once this is done, organizational strategic thinking must begin. Together with a SWOT analysis (strengths, weaknesses, opportunities, and threats) to establish the context related to an individual company (Strategic Analysis), the current state of objectives, customers, leadership, control, integration, 
processes, and results can be defined. (Strategic thinking). The same article also advises taking these elements and projecting them three to five years from now.

However, as mentioned earlier, the future is difficult to pinpoint, but not impossible. It requires the participation of a group of local leaders to resolve these questions, so the means are also important. Today, collaborative workshops have become an integral means of strategy development processes. They are considered $75 \%$ effective and help organizations to improve their understanding of the objectives for territorial development. Last but not least, they are conducted in short periods: no more than two or three days (Hodgkinson et al., 2005). Smith \& Looman (2015) researched within an Irish health center and highlighted the importance of developing a strategy map and balanced scorecard (BSC) to identify internal symptoms for quality improvement (QI), as an alternative method. Finally, the scenario planning method takes the best of human differentiators through shared storytelling and creating a sense of purpose.

Once the formulation process is complete, every territorial leader should not forget these five steps when the execution stage begins. These are a comprehensive vision that achieves coordination across departments and functions, strategic clarity at all levels before any flexibility of execution due to market volatility, finding the right combination of coordination, adaptation, and execution that will do more to create value (using territorial time, energy and resources correctly), building a culture of execution where everyone in an organization participates and identifies good data for future analysis and checks (Homkes, 2016).

\section{Opportunities to strengthen the impact of indigenous organizations through collective strategies}

Strategy formulation is not an organizational practice that should be put away in a drawer once it is completed. It is a necessary tool especially required in a new context where the main objective of territorial leaders and their organizations is now to set a course towards future and long-term sustainability. The holistic vision put forward by Homkes (2016) could even change the concept of seeking the profit of shareholders and business owners to that of Stakeholders, which fits more precisely in this new era where ethics and collective values predominate. That is why a strategy must collectively focus on itself.

Having said that, it is worth mentioning that the formulation of strategy brings with it important opportunities for organizations, administrations, and stakeholders. First, a well-defined strategy could lead local or indigenous businesses and organizations to an important opportunity to ensure their sustainability: a more intimate culture with the customer. Verwire (2014) concluded that this achieves a long-term relationship where the most valuable and profitable customers remain loyal, especially in sectors such as cultural tourism, Andean handicrafts, and indigenous agricultural enterprises. So, it is required to measure this with KPI's or have CRM support. It is no less important to note that $20 \%$ of customers generate $80 \%$ of revenue.

Another opportunity, despite a complete and efficient study of the competition, is the possibility to find current and potential differentiating scalable skills, compare yourself with "Super-competitors", companies with notorious competitive advantages, and eventually, take the necessary steps to become one of them if it is feasible (Hubbard et al., 2014). This could help turn an indigenous-based company focused on local products into a platform business in this new digital era. According to Altman \& Tripsas (2015), it now becomes imperative to migrate from offering the best products to developing the best network of complementors, without losing original attributes or identity. A complimentary report by Birkinshaw et al. (2016) illustrated the importance of making strategic alliances with startups and emerging ventures. This creates a knowledge-sharing atmosphere where the best capabilities are taught, and the digital transition becomes easier for a more traditional company. The results are compelling: the introduction of innovative products and the repositioning of both the traditional company and the startups. Finally, all these opportunities can lead to building Corporate Social Responsibility (CSR), a new interest especially recognized by local start-ups.

\section{Definition of the collective strategy based on the policies of its member organizations, administrations, and key stakeholders}

There are two ways in which organizations can think about strategy: individually and collectively. The first is the classic view of strategy in which chief executives were responsible for first refocusing their guidelines and then communicating the objectives and policies originated to the organization's teams and people in general. The problem with this conception is that it does not consider everyone's individual opinions or feelings. Therefore, it becomes necessary for leaders to first be able to identify people's own culture and the environment in which they live. 
Consequently, it is important to rethink the classic concept of the organization as a living entity, not only with objectives but also with particular values and ways of proceeding that are in line with the productive purpose and culture of the entire organization. Therefore, an organization and its strategy are formed from policies and values brought directly from the culture of the people, and its customers are part of the same society. Previously, it was mentioned that the paradigm of maximizing profits instead of helping humanity is so far an obsolete MSV plan (Clarke \& Friedman, 2016), as this same society is responsible for helping managers to achieve their goals through acquisitions of great variety. of value propositions. This view has morphed into a more holistic view, defined by Homkes (2016), where all efforts to shift to a more worthy culture must focus on stakeholders.

The stakeholders are a broad word that includes various strategic partners, external such as customers or suppliers, and internal as well. A true leader or manager must consider the human value that people bring every day and that helps them integrate within the organization, either with their co-workers or with their superiors. Secondly, Peter Drucker (1954) states that this new corporate strategy visualized collectively needs to be articulated and dynamic, trying to unify the individual ideas of each of the functional areas of the organization and the result would be a better adaptation to the political, social and operational environments. The strategy itself is proposed through various methodologies, whose first steps are to define the environment where the organization is located. According to Hodgkinson et al. (2005), strategy workshops are a common practice, often involving very senior managers, and such deliberations feed directly into the strategy development process. So, for example, practices such as PEST and/or SWOT analysis are mostly elaborated by these executives. In conclusion, this is not a collective way of defining strategy. What scenario planning teaches best is that interaction, shared storytelling and sense-making are important practices to be inspired by each member or team (Bowman, 2016). And this is where collective strategy works better than one in which only senior executives participate.

Finally, leaders should look for the right practices and procedures by applying strategy workshops so that workers feel more equal and involved in being part of this building that will define the future of the company. Approximately $75 \%$ of internal employees reported that the workshops provided effective input to the organization's strategic plan (Hodgkinson et al., 2005).

\section{Key political and strategic issues influencing collective strategy}

Collective strategy is the result of several decisions created through a methodological process that is made by the participants of an organization and its leader. As this pathway consequently generates strategic objectives, what gives them direction and meaning are the policies that organizations propose to finally involve everyone in the common strategy and fulfill the main objectives. These policies must be based on identity and diversity. The collective strategy would not be successful if it is not nourished by each employee's capabilities. The formation of a collective strategy comes about thanks to an organizational culture that must be based on diversity. Some key activities or factors that directly influence the collective strategy based on these policies could be:

- Coordinating the execution of the strategy among its multiple functions, departments, and units of the organization or community.

- Explicitly communicate the overall objective of the strategy and the non-negotiable aspects.

- Act flexibly and quickly in the face of local circumstances and changing market conditions.

- Balance activities, resources, and internal coordination and adaptation to constant external changes.

- The people designated as implementation leaders must be prepared to solve problems since they have direct contact with the different stakeholders.

- Maintain commitments and negotiations between the organization's partners and the management office when circumstances and the environment seem to change.

- Develop a simple organizational story that communicates what your path is, your competency, how you plan to achieve results, and what the priorities are to make this happen.

- Identify the financial resources, human resources, and time that create the most value and reallocate them as the situation develops locally.

- Generate a corporate culture of learning, tolerating mistakes and failures, giving space for collaborative innovation.

- Question data explore ambiguous patterns and develop alternative stories to ensure that strategy execution is based on current reality. 
How the ethical tensions of organizations, administrations, and key stakeholders can be resolved

Discrepancies can usually be found between how culture is taught from the time someone is young and growing up and how ethics can change what culturally seemed normal. And what can be useful for an organization is to identify the set of values that the two have in common and consequently develop a set of best practices that should be infused with culture and ethics. Even so, these practices are critical to establishing customer loyalty and non-flawed public opinion. Clarke \& Friedman (2016) detailed nine unethical habits to avoid from the old culture of maximizing value for partners and, therefore, what practices should be shared in strategic policies:

- Maintain transparent and reliable data in financial statements shared by accountants or organizational leaders.

- Prioritize capital investment aimed at more employment and greater benefits for all indigenous enterprises or organizations.

- Seek the satisfaction of the organization's members, even if this includes rethinking a product or service that could harm local heritage or environmental conservation.

- This satisfaction must be planned for the long term, making stakeholder loyalty a priority.

- An organization that pays its taxes and social dues makes it responsible in the sense that the investment is beneficial to people and the creation of better conditions for the organization and its territory.

- Additionally, it must develop and update environmental policies within its processes, seeking to keep its carbon footprint as low as possible.

- Hiring indigenous leaders with high innovation, creativity, and excellent experience in heritage issues and local economic development.

\section{Strategic intelligence in strategy development and formulation}

Strategic intelligence is at the heart of strategic planning, because, although the latter involves methodologies that help shape the long-term objectives and plans that are found in the conception of the strategy, strategic intelligence provides important input on how this strategy should be shaped, where the status quo is no longer a constant, where the new constant changes, and where problems are welcomed rather than rejected. It is even expected to stimulate the solution of old and new local problems to pose challenges that will take the organization down a new path.

As is common knowledge, strategies are designed, executed, and received by men and women with varied characteristics and needs. Although these individuals fulfill different roles in society, they do not act in the same way in all contexts. The common denominator that unifies this diversity for intelligent strategic planning is purpose. Diversity is essential if a collective strategy is planned because it would nevertheless revert to a top management strategy. The word purpose entails a common project that links material goods and the designation of productive tasks for the achievement of goals.

In this context, identity, commitment, trust, and loyalty become necessary to be open to all the possibilities that arise and shape the strategy. Strategic intelligence is based on these factors to find a tool for success (Strategic Thinking): First, it is necessary to dare to explore the unknown in terms of improvements, partner satisfaction, and future changes. User satisfaction is a pillar of every business model, not to mention it. Secondly, each member of the organization must assume that the process of change and adaptation is constant, because if there are no problems, as was said first, they must be discovered to generate solutions and, indeed, new challenging proposals. Thirdly, everyone must be encouraged to communicate their thoughts and reflections and be able to accept a positive or negative reception. It is no less important to recognize more experienced leaders with the same old thinking, as fresh new voices are created. Fourth, all people need to recognize that no one owns the truth, because in an organization or community all visions nurture the common sense that gives life to the strategy. Fifth, constant learning and development are at the heart of a strategic organization.

Therefore, strategic intelligence applied to the development and formulation of an organizational strategy is useful for interpersonal development in a climate conducive to the exchange of ideas with respect, empathy, and trust. Thanks to this next step, it is expected to be dialogue and the construction of a common story in which everyone will participate and move forward to reach a strategic action. Consequently, this story will be transmitted both to the members of the organization and to the public entities, who will contribute by participating in the planning of a future scenario. 
The practice of scenario planning as a strategic tool connects the distinctive essence of the human being (reasoning, communicating, and socializing), conceptualizing it as a practice of simplicity, where the complexity of thought is conjugated with the simplicity of action, necessary to understand and convey the complexity surrounding organizational processes (Bowman, 2016). In other words, scenario planning is nothing more than a communicative process and storytelling a speech act.

This simplicity helps shape two outcomes of this method: process and scenarios. The internal processes where most people have space are discursive, episodic, and practices that combine sense-making, organization, and narration. Scenarios are the product of this same process, where problems are identified and therefore new practices are designed to easily convey this conceptualization: scenarios. They are boundary objects that are transferred as knowledge across other strategic boundaries (Bowman, 2016).

The best-accepted way to communicate the complexity of scenarios is storytelling, and it has been cited above that this is an excellent practice for strategic intelligence, where all stakeholders are found to have a story to tell that would create value in a collaborative business model. Storytelling is not a light practice as it seems, because it is underpinned by a great deal of sense of purpose creation, in a cross-organizational way. Scenario planning is a structured, analytical, funnel-like activity where its main objective is the creation of multiple futures to help stakeholders re-perceive reality to improve strategic or policy decisions. Bowman (2016) brings the best of socialization of organizational or community challenges through participatory workshops can be seen in Table 1 .

Table 1

Example of collective strategic objectives formulated in a participatory manner with the indigenous Aymara community of the Andean Eco-Zone of Parinacota

\begin{tabular}{|l|l|}
\hline Component & Collective strategic goal \\
\hline Extreme poverty & $\begin{array}{l}\text { Advance in the reduction of extreme poverty in all localities located in the } \\
\text { High Andean ADI. }\end{array}$ \\
\hline $\begin{array}{l}\text { Access to educational } \\
\text { opportunities }\end{array}$ & $\begin{array}{l}\text { Contribute to access to education and lifelong learning opportunities for the } \\
\text { entire population, reducing the need to travel to the regional capital. }\end{array}$ \\
\hline Access to adequate housing & $\begin{array}{l}\text { Guarantee quality housing with the corresponding basic services in harmony } \\
\text { with the traditional architecture of the Andean localities. }\end{array}$ \\
\hline Structural Racism & $\begin{array}{l}\text { Reduce racism and discrimination experienced by indigenous individuals, } \\
\text { families, and communities through the implementation of public policies. }\end{array}$ \\
\hline Depopulation & $\begin{array}{l}\text { To reduce territorial inequality between the ADI and the municipality of } \\
\text { Arica by improving the quality of life and creating economic opportunities. }\end{array}$ \\
\hline Climate change & $\begin{array}{l}\text { To prepare families and communities for the problems that may arise from } \\
\text { climate change to prepare mitigation and adaptation measures. }\end{array}$ \\
\hline $\begin{array}{l}\text { Access to economic } \\
\text { opportunities }\end{array}$ & $\begin{array}{l}\text { Develop and make productive activities compatible within the framework of } \\
\text { cultural identity and sustainability as a policy for overcoming poverty. To } \\
\text { this end, it is necessary to create business development centers adapted to the } \\
\text { specificities of the Aymara culture. }\end{array}$ \\
\hline
\end{tabular}

Source: Dante Choque \& Rodrigo Barra, 2019

\section{The collective strategic aspirations and the moral, cultural, and operational aspirations of the organizations}

As collective strategies are based on the conviction that personal skills build a more consistent strategy, taking the best from each member and with the willingness to learn from constant changes, their aspirations indeed arise from the network of social relationships that day by day unites individual values and helps people learn from each other. Yes, it is important to be outwardly sensitive, but it is essential to be inwardly sensitive to other colleagues who also represent a source of knowledge. Ultimately, space, where everyone can share ideas, is beneficial to deepen external studies and analysis. This is also related to the ethical, cultural, and operational objectives of the organizations and stakeholders.

Therefore, the collective strategy is conditioned by the thoughts, feelings, values, and decisions of the people who are part of the organization. It should be pointed out again that an organization is a living entity, with objectives, policies, beliefs, a culture, particular values, and ways of proceeding. All these elements must be enlisted, known 
vertically and horizontally, and adapted to the productive purpose of the value chain. Thus, a successful organization consolidates a social and moral culture that is integral and manages to represent each of the people who are part of the operational areas of the organization, no matter how different they may be. As a result of this process, the construction of a common history would become a reality, where participation would be shared, both in the planning and execution of the strategy. In any case, a well-constituted culture will undoubtedly result in a value proposition that guarantees the satisfaction of the various stakeholders. Consumers are also part of a cultural environment, so they could show empathy towards this new fresh vision of the business with ethnic origin.

\section{Conclusions}

The search for economic development pursued by the Chilean government and many sectors of national society has serious repercussions on the lives of Chile's native peoples. The case of the Aymara people is an example since the main natural and patrimonial resources are located precisely in indigenous territories. Contrary to this position, the current state policies and collective development have demonstrated their lack, added to the lack of technical assistance and subsidies that promote sustainable development, decentralized and overcoming poverty, at a tangible pace that motivates collective participation and increases both individual and associative capacities.

The importance of the topic motivates the purpose of this article, exploring the theory and practice of collective strategy in organizations that wish to remain sustainable, since worrying only about individual "value" is not enough to enhance the endogenous resources of the territory. As the indigenous productive system is complex and integrates diverse activities, including agriculture, handicrafts, and camelid livestock, and the world is changing rapidly, new models and long-term strategies must be developed.

All these activities require an urgent paradigm shift, as they are not based solely on methodological tools such as the Balanced Scorecard, SWOT, PESTEL, or Scenario Planning. Scenario Planning lays the foundation for smarter strategic planning. Consequently, Strategic Thinking needs a different critical approach in organizational, philosophical, and methodological dimensions, different from the usual strategy workshops. Moreover, change is seen as the only constant, and innovation and participation support this assertion.

In this context, leadership in collective strategy requires two main considerations that could summarize the whole essay, one at the managerial level and the other at the organizational level. The first considers the need for leaders open to innovation and new ideas. Territorial leaders who can allocate their time to address urgent needs such as planning development activities, building relationships, receiving honest feedback on how the work is being done, focusing on collective development, and exploring new improvements, iterations, or modifications of the local value proposition.

"The second is strategic planning, which would act under a narrative logic that will allow a simple and immediate flow of information, for successful activities to be taken and for a correct deployment of the organizational strategy, in real-time and following these principles: a holistic vision, strategic clarity at all levels, finding the right combination of coordination, adapting to actions to create value, building a culture of execution where everyone in an organization participates" (Homkes, 2016).

Finally, the article exploring the importance of collective strategy to support indigenous Aymara development corresponds in any case to the current view of the marginalization of the indigenous context within the global system. In this sense, the conventional vision of development, as a process especially reduced to raising productivity through technical progress, inspired from external institutional structures, are not necessarily effective and respectful of local collective strategies. In other words, and as stated by Dr. José Luis Sampedro (2019), "Action on local structures, to make them evolve along the dimension of social change is indispensable for an authentic development, demanding an alternative path", based on a collective strategy with greater participation and commitment of the economic and institutional agents of the territory.

\section{References}

Altman, E. J., \& Tripsas, M. (2015). Product to platform transitions: Organizational identity implications. The Oxford handbook of creativity, innovation, and entrepreneurship, 379À394.

Andrews, K. R. (1971). Concept of corporate strategy.

Barber, B. M., Odean, T., \& Zheng, L. (2005). Out of sight, out of mind: The effects of expenses on mutual fund flows. The Journal of Business, 78(6), 2095-2120.

Birkinshaw, Robbins \& Ryan. (2016). "How to become familiar with digital transformation".

Bowman, G. (2016). The practice of scenario planning: an analysis of inter-and intra-organizational strategizing. British Journal of Management, 27(1), 77-96. https://doi.org/10.1111/1467-8551.12098 
Chandler, A. (1962). Strategy and structure. The MIT Press, Cambridge, MA.

Clarke, C., \& Friedman, H. H. (2016). 'Maximizing Shareholder Value': A Theory Run Amok. Clarke, Clifton \& Friedman, HH (2016). Maximizing shareholder value: A theory run amok. i-manager's Journal on Management, 10(4), 45-60.

Dante \& Barra (2019) Elaboration of participatory strategic planning for the Eco-Zones of the High Andean ADI, year 2009. DICG.

Davis, J. H., Schoorman, F. D., \& Donaldson, L. (1997). Toward a stewardship theory of management. Academy of Management review, 22(1), 20-47.

Drucker, P (1954). The practice of management. Harper, New York.

Drucker, P. F. (1954). Management by objectives and self-control. Practice of management.

Hodgkinson, G. P., Johnson, G., Whittington, R., \& Schwarz, M. (2005). The role and importance of strategy workshops: findings of a UK survey.

Hoffman (2014). Strategies companies are using to mitigate and adapt to climate change.

Homkes, R. (2016). Translating strategy into results. London Business School Review, 27(1), 34-37.

Hubbard, Leinwand and Mainardi (2014). "What your company can learn from super competitors".

José Luis Sampedro (2019) "Humanist Economics; Something more than figures". ISBN: 978-84-9908-178-6

Kaplan, R. S., \& Norton, D. P. (1998). Putting the balanced scorecard to work. The economic impact of knowledge, 27(4), 315-324.

Kourdi (2010). "The future is not what it used to be."

Meabh Smith, John Loonam, (2016) "Exploring strategic execution: a case study on the use of the balanced scorecard in an Irish hospital", Journal of Strategy and Management, vol. 9 Issue: 4, pp. 406-428.

Penrose, R. (1959, January). The apparent shape of a relativistically moving sphere. In Mathematical Proceedings of the Cambridge Philosophical Society (Vol. 55, No. 1, pp. 137-139). Cambridge University Press.

Popp, J., Petö, K., \& Nagy, J. (2013). Pesticide productivity and food security. A review. Agronomy for sustainable development, 33(1), 243-255.

Smith, M., \& Loonam, J. (2016). Exploring strategic execution: A case study on the use of the balanced scorecard within an Irish hospital. Journal of strategy and management.

van Marrewijk, A. (2016). Conflicting subcultures in mergers and acquisitions: A longitudinal study of integrating a radical internet firm into a bureaucratic telecoms firm. British Journal of Management, 27(2), 338-354.

Verweire (2014). "How to be a customer-intimate company."

Verweire (2014). "How to formulate a winning strategy."

Willis (2015). "The ABCs of CSR. Corporate social responsibility programs are easy to get wrong." 